\title{
A Pesquisa Clínica em PSiCANÁlise 1
}

\author{
Marie-Jean Sauret ${ }^{2}$ \\ Université Toulouse II - Le Mirail-Toulouse - France
}

\begin{abstract}
A pesquisa em psicanálise pertence a uma nova etapa da ciência moderna: no campo da matemática, admitindo que ela seja consistente, concluiu-se que existem proposições verdadeiras que não são demonstráveis, revelando a incompletude do sistema. Isso teve efeitos sobre as várias áreas do saber. É nesse contexto que Lacan se empenha em formalizar o discurso analítico e produzir os matemas suscetiveis de indexar o real em jogo na experiência psicanalítica.
\end{abstract}

Descritores: Psicanálise. Ciência. Clínica psicanalítica. Pesquisa.

Dara falar dessa questão, convém, antes de mais nada, fazer uma exposição sumária sobre as relações da psicanálise com a ciência. Essas relações dependem da natureza da ciência moderna. Extraio dessas relações, desenvolvendo-as mais ou menos, três características.

\section{Psicanálise e ciência}

1. A ciência moderna nasce no século XVII com a descoberta de que o saber acumulado, até então, apresenta um limite e de que descobertas novas

1 Conferência proferida em setembro de 1999, a convite do Professor Luiz Carlos Nogueira, do Instituto de Psicologia da USP, no programa de pós-graduação em Psicologia Clínica. Tradução: Sílmia Sobreira, psicanalista, membro da Escola de Psicanálise do Ca mpo Lacaniano - Fórum de São Paulo.

2 Psicanalista e professor da Faculdade de Psicologia da Universidade Toulouse II Le Mirail. Endereço para correspondência: Université de Toulouse - Le Mirail (Toulouse II). 56 alléss Antonio Machado, Toulouse, France - 31058. 


\section{Marie-Jean Sauret}

são suscetíveis de demonstrar sua caducidade. Foi assim com a descoberta por Kepler do fato de que os astros não giravam de uma maneira tão regular como o afirmava Ptolomeu, ou com a descoberta por Galileu de que a Terra girava sobre ela mesma e em torno do sol, contra o que a teologia lia na Bíblia. Esses e outros achados tiveram sobre os contemporâneos desses cientistas o mesmo efeito que o provocado sobre alguns de nós pelo fim de um mundo separado em dois blocos pela cortina de ferro - mundo que acreditávamos eterno! Temos uma idéia desse abalo através da leitura dos debates em torno do processo de Galileu: o universo ptolemaico desmoronava. Diríamos, hoje, que a ciência moderna aparece com a descoberta do real como o que põe em cheque o saber e provoca uma nova elaboração. Só que, daí em diante, o cientista sabe que todo saber está à mercê do real.

2. Cabe a Descartes dar os fundamentos da nova ciência. Sensível ao desmoronamento dos saberes, ele se pergunta como obter uma certeza, se o cientista não aceita mais a garantia do mestre antigo: "É verdade porque Sócrates, Platão, Aristóteles, Ptolomeu, Hipócrates etc. o disseram". Ele é obrigado a constatar que basta questionar os diversos saberes para que cada um deles se torne incerto. Daí ele conclui, então, que tinha nas mãos uma prova lógica da existência do sujeito: é preciso, de fato, que eu exista se, por questionar o saber, eu lhe retiro toda certeza e nele introduzo um pouco de desordem! "Duvido, penso, portanto, eu existo".

Sem dúvida, seu golpe de gênio reside na colocação em evidência da clivagem entre a verdade e o saber (ele deixa para Deus o encargo da primeira), e a emancipação do sujeito do Outro divino - em matéria de saber.

3 O Cogito assegura o sujeito do que ele é como tal, mas o que há de mais certo não depende da experiência de seus sentidos, mas de uma causa situada no Outro - $e$ mancipação do sujeito fora do Outro divino. O sujeito se emancipa da verdade garantida por Deus, em benefício de uma verdade que repousa sobre si mesma, da qual Deus é a testemunha. Emancipação de uma certeza - "eu estou certo porque Deus o disse" - por uma certeza outra - "tenho certeza porque o demonstro". Descartes rompe, assim, com a herança grega e medieval, menos no transtorno dos saberes que na inversão das relações do cientista com o cosmo. No sentido estrito, não há ciência do homem, pois, ao homem e a Deus, Descartes substitui como condição da ciência, o sujeito e o Outro. Este sujeito não é viável nem apto ao conhecimento, falta diante de um Outro ao mesmo tempo completude, alteridade e campo, onde se situa a causa eficiente. Esta conclusão poderia tornar vã a ciência, uma 
Salientemos uma ou outra conseqüência:

- um crítico bem intencionado poderia fazer a Descartes a observação de que ele não precisa desse desvio para estar assegurado de existir: a experiência dos sentidos;

- a percepção do tato ou da visão - respondem antecipadamente. Mas é justamente o que recusa Descartes, diante da constatação de que séculos de percepção não impediram os homens de ciência de sustentar como verdadeiro o que havia de falso no saber dos gregos antigos. A resposta de Descartes a seu detrator se limita a duas palavras: "demonstre-o";

- o mesmo crítico tentará fazer a Descartes a observação de que foi realmente necessário que Kepler e Galileu fossem à janela para se aperceberem dos erros de Ptolomeu. Falso, retruca ainda Descartes. E ele poderia citar Galileu (que ele critica por não ter fundamentado na razão sua física matemática) que explicava que, se houvesse a pretensão de questionar a natureza, seria necessário fazê-lo em linguagem matemática, uma língua precisamente sem sujeito que nela introduzisse aparentemente a desordem. Aliás, Galileu teria sustentado a verdade da lei da queda dos corpos contra a evidência estatística que a teria desmentido, se ele tivesse jogado duas bolas de massa igual, mas de volumes diferentes do alto da torre de Pisa: a lei matemática tem razão sobre a experiência ${ }^{4}$;

- o sujeito é excluído do saber da ciência, de um lado, pelas razões ligadas às exigências da objetivação, da generalização e da universalização; de outro lado, porque, se o saber é já constituído e verificado junto a Deus, então o cientista não pode desejar saber, a menos que seja, assim, excluído do mesmo saber e do que garante sua verdade;

- enfim, o mais importante para nós reside no fato de que Descartes indica, ao mesmo tempo, que não há ciência sem o desejo de um cientista que a fabrica, mas que convém tentar apagar do saber produzido todo vestígio do sujeito (tanto do lado cientista do sujeito como do lado objeto do su-

vez que ela estaria já em Deus: ele é a ciência que não pode me enganar! Mas como é possível, justamente, que o sujeito seja assim definido fora da ciência, que ele esteja na não ciência, onde lemos a razão do embaraço das disciplinas "especialistas" do sujeito?

4 Cf. Xenoyanni (1999). 
jeito), se pretendemos que o saber alcance a universalidade, o generalizável. É justamente o que permitiria, senão a linguagem matemática falada tanto pelo cientista como pelo objeto estudado, ao menos a lógica como ciência do real.

Pertencemos a uma nova etapa da ciência moderna. Destacarei, apenas, uma característica para nós. A física atual nos demonstra não apenas que não se pode prescindir do sujeito que fabrica a ciência, mas que é necessário levar em conta a presença do observador em resultados impossíveis sem essa presença (notadamente em física quântica). Sobretudo, os matemáticos se apercebem que não é possível fiar-se absolutamente na matemática, que sua consistência, sua completude não são demonstráveis. De sorte que a matemática se desenvolve sob a ameaça de encontrar um enunciado que demonstraria o caráter errôneo daqueles que o precedem. A matemática tem, igualmente, assim, a ver com a hipótese do encontro de um ponto que ela não pode pensar: ela tem seu real!

Não se trata de sustentar a tese do relativismo da ciência, como a que é promovida por uma certa filosofia atual, mas, ao contrário, a existência desse real. Cientistas como Prigogine tiram disso algumas conclusões, afirmando que estamos na era do "fim das certezas". Ao dizer isso, eles não afirmam que não podemos estar certos de nada, mas produzem teorias certas da incerteza: cálculos de probabilidades, teoria das catástrofes, teoria dos fractais, das cordas etc. Os matemáticos não duvidam: eles se esforçam para dar uma demonstração da impossibilidade lógica de demonstrar certas sentenças num sistema dado.

\section{Fixemos estes pontos:}

- a ciência moderna rompe com a posição epistemológica de Aristóteles, que dá prioridade à coisa existente e, portanto, ao laço que liga a ela o sujeito que percebe por meio dos sentidos;

- o sujeito, enquanto particularidade a ser eliminada tanto do objeto como da língua na qual a ciência se desenvolve, é um "buraco no saber";

- a ciência não poderia se livrar dos limites do saber para ir dar uma volta do lado do real, simplesmente ao deixar que se nomeassem seus mecanismos lógicos. É necessário um sujeito que seja orientado, precisamente, pelo que ele não sabe - paixão da ignorantia docta. Nesse sentido, só há real para 
um sujeito; se a matemática, os discursos, as práticas etc. têm seu real, é sempre com a condição de que haja um sujeito que consinta em "esbarrar" nele.

\section{O nascimento da clínica}

O advento da ciência moderna permite o desenvolvimento de uma clínica médica. Os êxitos dessa clínica estão na origem da descoberta e do isolamento de um campo que a ela resiste, tanto no plano da explicação como da terapêutica. Daí a hipótese segundo a qual as chamadas patologias diriam respeito menos ao organismo do que a esse sujeito que a ciência se esforçaria para evacuar. Assim, nasce o postulado, entre o organismo e um certo número de patologias, de uma variável intermediária, o psiquismo ou o mental. Psiquismo e mental são significantes inventados nesse uso para tentar fazer o sujeito entrar novamente no discurso da ciência... Sem dúvida, os pesquisadores pensam conseguir, assim, um tratamento objetivo do dito sujeito, sem perceberem que reiteram, no seu nível, essa tentativa de exclusão do sujeito, constitutiva da ciência moderna.

Um estudo exaustivo deveria levar a observar que esse período, sob a dupla influência da embriologia e do darwinismo, vê, também, o aparecimento das psicologias do desenvolvimento e da criança, caracterizadas pela observação longitudinal de casos individuais - os próprios filhos dos pesquisadores. Supõe-se, assim, que o cientista assiste, no nível do desenvolvime nto do indivíduo, a um resumo das etapas que permitiram à humanidade emergir do mundo animal. Adivinha-se que o humano está reduzido a determinações biológicas, psicológicas e sociais, situadas na infância e aquém, e agindo em interação com variáveis do meio ambiente. O indivíduo é um produto.

\section{A clínica psicanalítica}

E a psicanálise nisso? É claro que ela é filha da ciência, no sentido de que ela não seria possível sem a produção do sujeito da ciência. Sem dúvida, seria necessário examinar suas condições de invenção: seja por Freud aí encontrar uma resposta ao que o atormenta, seja pelo declínio das imagos 
paternas (e não forçosamente da função paterna) promovido pela ciência, que condicionam essa invenção... De qualquer modo, a psicanálise tem esse privilégio de ser a única disciplina que tem o desígnio de não renunciar a dar a palavra ao sujeito, a não renunciar àquilo que constitui sua particularidade. Ela não poderia, pois, ser uma ciência como as outras e, em particular, uma ciência do sujeito, uma vez que essa ciência do particular, e um particular que fala uma outra língua que não a matemática, é contraditória em termos.

Para situar a psicanálise, apresentarei algumas proposições.

1. A psicanálise se desenvolve em três planos indissociáveis ${ }^{5}$ :

- como método de investigação dos processos psíquicos (associação livre, escuta flutuante, transferência etc.);

- como método de tratamento inventado para e com os neuróticos (daí o problema do tratamento dos psicóticos trazido por Lacan);

- como teoria dos fatos impossíveis de serem colocados em evidência sem esse método de exploração e de tratamento.

Afirmar que esses três níveis são indissociáveis equivale a dizer que toda mudança ou descoberta em um nível exige uma mudança ou uma invenção nos demais. Toda paralisia num plano acarreta uma paralisia nos outros e, mais gravemente para nós, isso significa que isolar um nível - o que vamos tentar a propósito da pesquisa - nos tira da psicanálise propriamente dita, de suas condições de elaboração e de verificação. Manter de uma maneira ou de outra o enodamento entre esses três registros é mais do que uma questão científica: é uma questão ética. Para dizer a verdade, a psicanálise e a pesquisa que ela permite - não se mantém à altura das exigências da ciência, sem correr o risco de reduzir-se a ela (e de suprimir o sujeito assim como a verdade que o causa), a não ser preservando sua ética!

É assim que Lacan, que situa o terapêutico do lado de um efeito "a mais", observa "que a teoria e a prática (...) não podem dissociar-se uma da

5 A referência é conhecida. Freud afirma que a psicanálise é o nome: "1. De um procedimento de investigação dos processos psíquicos, que, de outra forma, mal seriam acessíveis; 2. de um método de tratamento das perturbações neuróticas que se baseia nessa investigação; 3 . de uma série de concepções psicológicas obtidas por esse meio e que se fundem progressivamente em uma disciplina científica nova'" (Freud, 1923/1984, p. 51). 
outra, e a partir do momento em que se concebe a experiência em um sentido, é inevitável conduzi-la igualmente nesse sentido" (Lacan, 19561957/1995).

2. A psicanálise se interessa pelo que constitui o particular do sujeito, aquilo pelo qual o sujeito resiste à ciência. Mas ela vai tentar tratá-lo por meios dignos do discurso da ciência que o isolou. É nesse contexto que Lacan se esforça para formalizar o discurso analítico, para produzir a lógica operante, para produzir os matemas suscetíveis de indexar o real em jogo, despojando-o das aderências imaginárias das quais as significações são portadoras.

3. Já é um resultado: sabemos do que é feito esse mais particular do sujeito rebelde a todo saber, e onde podemos ler o real do sujeito - trata-se de seu ser de gozo, tal como é produzido ao termo de uma análise, no sinthome ao qual o sujeito se identifica.

4. Sabemos, também, qual é o problema maior do sujeito e, ao mesmo tempo, da psicanálise que o acolhe: como o sujeito conseguirá localizar o mais particular de seu gozo no laço social sem que, de um lado, esse particular não seja reabsorvido no social, mas, por outro lado, sem que o laço social se desfaça no rochedo do particular (na reivindicação histérica ou no "a cada um sua verdade", por exemplo).

5. Enfim, lembremo-nos de que para Lacan a análise constitui o dispositivo experimental adequado para estudar a relação do sujeito com a linguagem, com o gozo e com seu desejo. Releiam, a esse respeito, a Tese I que Lacan expõe no início de seu artigo sobre "A Agressividade em Psicanálise":

Podem seus resultados fundar uma ciência positiva? Sim, se a experiência for controlável por todos. Ora, constituída entre dois sujeitos, dos quais um desempenha no diálogo um papel de impessoalidade ideal (...), a experiência, uma vez consumada, e unicamente sob as condições de capacidade exigível para qualquer investigação especial, pode ser retomada pelo outro sujeito com um terceiro. Essa via aparentemente iniciática é apenas uma transmissão por recorrência, com a qual não há por que nos surpreendermos, já que ela se prende à própria estrutura, bipolar, de toda subjetividade. Somente a velocidade de difusão da experiência é afetada por ela, e, se sua restrição à área de uma cultura é discutível, não só nenhuma antropologia sadia não pode extrair disso uma objeção, como tudo indica que seus resultados possam ser suficientemente relativizados para uma generalização que sa- 
tisfaça ao postulado humanitário, inseparável do espírito da ciência. (Lacan, 1998a, p. 106)

Assim, Lacan escreve, em outro lugar, num outro tom: "Mas a análise não é uma religião. Ela procede do mesmo status que a ciência. Ela se engaja na falta central na qual o sujeito se experimenta como desejo" (Lacan, 1964/1985).

Contudo, a verificação do operador da análise, o desejo do analista (o que está escrito acima sob a forma do "papel de uma impessoalidade ideal", por trás da qual é preciso ler a posição do analista em posição de objeto causa do desejo do analisante) levará Lacan a inventar um outro dispositivo quase experimental: o passe. Contentemo-nos em dizer que o passe verifica que a psicanálise não é um delírio, que o efeito esperado está realmente no encontro marcado do final. Se a psicanálise for um delírio, então, tudo o que pudermos afirmar sobre uma pesquisa clínica de orientação analítica (mais que de inspiração) é caduco.

\section{As pesquisas psicanalíticas}

Os pesquisadores que se interessam por este tema não deveriam desconsiderar a psicanálise. Mas caem sob o golpe de duas injunções contraditórias:

- de um lado, se a psicanálise tem razão, a estrutura do sujeito é em todos os lugares a mesma;

- por outro lado, o que valem os conceitos da psicanálise e a própria pesquisa psicanalítica transportados fora do dispositivo da análise ${ }^{7}$ ?

6 Toda a tese deve ser lida.

7 “... o saber da psicanálise não é inefável nem limitado unicamente a seus iniciados: se o sujeito for realmente o que dele diz a psicanálise, então, isso deve poder se verificar fora do divã. Certamente. Mas em que condições?", escrevíamos já em Conditions méthodologiques d'une recherche clinique se référant à la psychanalyse dans le champ des STAPS (1997, p. 167). 
Indicarei, aqui, algumas pistas que permitem, contudo, alguns passos seguros.

1. O próprio Lacan evoca uma observação esclarecida pela psicanálise: ela consiste em referir os fatos de observação à estrutura. Mas isso supõe assegurar-se de que os fatos de observação em questão dão testemunho da relação do sujeito com o significante. Para tomar um exemplo: ao estudar a proibição do incesto entre os habitantes de Trobriand, Malinowski demonstra a pertinência da tese freudiana sobre o caráter universal do complexo de Édipo, ao mesmo tempo em que apresenta seus resultados como uma objeção (já que não é o pai biológico que educa a criança, mas o irmão da mãe). Ao contrário, os biólogos que pretendem estender a proibição do incesto ao mundo animal, sob o pretexto de que os jovens machos são afastados da horda, dão testemunho apenas de uma confusão. O que constitui a proibição do incesto não é o fato de que uma determinação biológica impede o coito com um consangüíneo, mas o fato de haver um interdito linguageiro de relações sexuais entre dois parentes, consangüíneos ou não, e que os sujeitos tenham a memória simbólica desse interdito, uma vez que ela inaugura uma ordem.

2. Não há pesquisa clínica sem encontro que mobilize a palavra. Dizendo de outra forma, todo ato de palavra que mobiliza um encontro entre um sujeito e um outro (quer o pesquisador seja o agente, o parceiro ou apenas testemunha da relação) é suscetível de uma avaliação com os elementos da estrutura. Este dispositivo, que pode ser o de uma entrevista clínica de pesquisa, apresenta suas cartas de nobreza com um outro dispositivo refundado por Lacan: a apresentação clínica. O sujeito consente em falar com um psicanalista, diante de um público, da forma como ele se dá conta de seu funcionamento, do que lhe aconteceu, de sua relação com o mundo, de sua forma de encarar o futuro. Este dispositivo é, no fundo, apenas uma extrapolação das entrevistas preliminares a todo tratamento analítico, nas quais o analista se esforça para extrair as condições que tornarão a análise possível ou que verificarão que o sujeito deseja preservar sua liberdade de "não transferência", e onde ele se esforça para estabelecer um diagnóstico estrutural, a partir do qual ele começará a se orientar.

3. Sem dúvida, podemos nos autorizar a partir do próprio Lacan a distinguir psicanálise e método psicanalítico, sem tornar pejorativo este último: 
A psicanálise só se aplica, em sentido próprio, como tratamento e, portanto, a um sujeito que fala e que ouve. Fora desse caso, só pode tratar-se de método psicanalítico, aquele que procede à decifração dos significantes, sem considerar nenhuma forma de existência pressuposta do significado. (Lacan, 1998b, p. 758, grifo nosso)

Essa decifração dos significantes sem pressuposição parece exigir uma decifração dos significantes que leve em conta o aspecto inconsciente que intervém na organização deles. Uma decifração sob essas condições deveria conduzir ao encontro da "própria estrutura do sujeito que a psicanálise delineia" (Lacan, 1998b, p. 758, grifo nosso). O método psicanalítico dá a palavra ao sujeito, leva em conta o efeito de falta introduzido pela linguagem e permite que essa falta fundamentalmente inconsciente seja mantida. O método mantém a ética da psicanálise enquanto ela preservar essa falta como causa do desejo... e enquanto ela der a prova de sua articulação ao discurso analítico.

4. Só o dispositivo freudiano da análise permite ao sujeito engendrar o que ele é de irredutível ao saber e que Lacan indexa pelo objeto $a$ e pela identificação ao sintoma. Sem dúvida, é o único registro no qual os quatro conceitos fundamentais da psicanálise encontram sua pertinência: inconsciente, transferência, repetição e pulsão. O método psicanalítico é, no fundo, constituído daquilo que, pela experiência da análise, é transponível fora dela, sem romper o laço com o discurso analítico. Uma concepção do sujeito como falante e dividido, a hipótese do inconsciente como fundamento de todo fato psíquico, o que implica verbalização (entrevista), escuta, a análise, transferência, intervenção (ainda que a imposta pela consequiência do encontro). ${ }^{8}$

5. Sabemos que não há real senão para um sujeito. O real se manifesta sob a forma de um enigma, de um limite do saber, de um gozo insuportável etc. A pesquisa encontra um campo privilegiado no exame das respostas do sujeito. Um dos domínios de predileção é constituído pelas criações: científicas, pictóricas, poéticas, e também as próprias criações psicanalíticas (mas, então, é do lado do passe que convém ir ver ainda). A pesquisa explora como um sujeito traz a sua contribuição ao que torna a humanidade mais humana - em função de sua própria estrutura. Pois o que o sujeito trata não são apenas os limites da arte ou da ciência, mas o que ele próprio é como obje-

8 Aqui, apóio-me em um trabalho inédito de Luz Mery Zapata (1999). 
ção ao saber: de sorte que sua criação traz a marca própria de seu gozo, o que chamamos um estilo.

6. A questão da criação e do estilo é indissociável de outro campo de investigação: como o sujeito conseguiria localizar o que há de particular com o laço social? Já conhecemos o problema: como o sujeito inscreveria no social o mais particular de seu ser de gozo, sem dissolver essa particularidade no mesmo social (sob a forma de um saber científico universal, por exemplo, ou "cedendo a seu desejo" etc.), e sem que o laço social se esmigalhe em tantos sujeitos? Conhecemos, igualmente, a resposta, o sintoma - na escrita que Lacan prefere, quando ele preenche essa função: sinthome.

Parece-me necessário distinguir, depois dessa enumeração, diferentes tipos ou formas de pesquisa ${ }^{9}$ :

- a que visa a responder a questões colocadas pela psicanálise;

- a que visa a responder a questões colocadas à psicanálise;

- a que visa a construir uma teoria a partir da doutrina e da experiência;

- a que visa a ampliar o campo da experiência analítica;

- a que é somente orientada pelo saber e, eventualmente, pela ética da psicanálise. O que nos leva a distinguir entre a pesquisa psicanalítica - a dos psicanalistas (e essa dimensão existe, aliás, em Freud, Abraham, Lacan, Winnicott...) - e a pesquisa que se apóia sobre a psicanálise e que é orientada por ela. Evidentemente, na universidade, a pesquisa é mais frequientemente uma pesquisa que se apóia sobre a psicanálise e é orientada por ela - com exceção da pesquisa efetuada por psicanalistas que contribuem para ela a partir de sua prática.

\section{Alguns resultados notáveis}

1. Nossa própria equipe (Sidi Askofaré, Michel Lapeyre, Elfakir Abdelhadi) empreendeu um estudo sobre os acidentes do laço social: violências coletivas, passagens ao ato, aumento do suicídio de crianças, multiplicação das relações de agressões sexuais contra as mulheres e as crianças etc. Essa

9 Tomo emprestada essa judiciosa enumeração a meu colega e amigo Sidi Askofaré. 
pesquisa nos levou a especificar a natureza do laço social contemporâneo, o discurso capitalista.

Uma tese de Lacan veio para o primeiro plano: o discurso capitalista se sustenta pela exclusão do sexual, isto é, pela foraclusão da castração. Ele leva a crer, com efeito, que o sujeito pode encontrar no mercado o objeto que a ciência fabrica para satisfazer seu desejo. Privado da possibilidade de simbolizar a falta estrutural de gozo, o sujeito responde, constituindo-se como indivíduo. Esse indivíduo, do qual um dos modos de resposta privilegiada à intrusão do gozo (em falta ou em excesso) tem todas as características daquilo que alguns se esforçam para inventar como quarta estrutura (por não levar em consideração o laço social): estado limite ou border-line. Como recompensa, a formalização do discurso analítico por Lacan nos permite designar o que fica esquecido pelos teóricos dos estados limites: o discurso analítico é o único que considera o outro como sujeito! Por isso, nenhuma pesquisa psicanalítica digna desse nome deveria desprezar essa dimensão.

Outros resultados mereceriam ser destacados: por exemplo, não é certo que o número de agressões sexuais tenha realmente aumentado. Mas é certo que a natureza delas mudou: não é a mesma coisa transgredir o interdito do incesto, por estar operando um desejo perverso e considerar as mulheres e as crianças, quaisquer que sejam, como objetos sexuais colocados no mercado.

2. Uma doutoranda de nossa equipe, Luz Mery Zapata ${ }^{10}$, trabalha com as manifestações linguageiras da neurose. Confesso que eu não pensava que ela obtivesse grandes resultados, já que a dimensão da enunciação, do dizer, é, por definição, rebelde ao enunciado, e que os jogos de palavras, os lapsos etc. não me pareciam permitir uma particularização dos discursos sustentados por sujeitos em função do tipo de neurose. E depois, como estar seguro do diagnóstico?

10 Luz Mery Zapata, Clinique Différentielle des Névroses. Une Approche Psychanalytique à partir de l'Étude du Langage, tese de psicopatologia em curso; Clinique Différentielle des Névroses et Analyse de Discours. Essais d'Application sur um Corpus d'Entretiens Cliniques de Recherche, trabalho apresentado no Séminaire Interdisciplinaire d'Analyse de Discours, coordenado por François Leimdorfer e Paul Wald, IRESCO, Paris, 16 de abril de 1999. 
A autora explora, para fazer isso, um logicismo da informática que permite distinguir classes de arganização da linguagem: um pouco como constantes que caracterizam um sujeito e que Luz Mery Zapata aproxima do que Lacan chama "lalíngua". Mas essa análise confrontada com o desenrolar das entrevistas permite, além disso, destacar dois outros níveis: (a) a dimensão do acontecimento narrativo (a historização segundo a fantasia própria de cada um); e (b) o registro da enunciação apreendido através das manifestações do engajamento do sujeito em seu dizer e os entraves, mesmo no ato de fala - no fundo, tudo o que é preciso cortar de um registro para reduzi-lo a um enunciado legível como um artigo!

Recentemente, tive a surpresa de encontrar uma confirmação desses resultados em um estudo de C. Mejia e F. Ansermet que utilizam o mesmo logicismo, a propósito de um outro objeto de estudo: o traumatismo. ${ }^{11}$ Essa conjunção é uma espécie de verificação da possibilidade de uma certa generalização dos resultados obtidos por uma pesquisa de orientação analítica. Mas os autores conseguiram pôr em evidência uma lição da análise: uma correlação entre a utilização de uma rede sintagmática fechada, incluindo sintagmas congelados, e a experiência traumática. Em outros termos, o sujeito não fala quando se trata do traumatismo, mas repete as significações do Outro. Disso, eles deduze m o que é, ao mesmo tempo, uma lição da lingüística saussuriana e da psicanálise: as falas não podem se descongelar, a não ser por uma "simpatia lingüística" (entre próximos, diz o lingüista; mobilizando a transferência, corrige o psicanalista). Evidentemente, esta última observação introduz uma dimensão ética: o pesquisador poderia considerarse desobrigado pelos resultados, sem que a relação que ele inaugurou visasse a criar as condições desse degelo?

\section{Para concluir}

Esta apresentação está um pouco ampla. Mas parece-me que ela permite sustentar:

11 C. Mejia \& F. Ansermet, Traumatisme et Langage. Notes pour une Méthodolologie de Recherche Clinique. 
1. A pesquisa psicanalítica contribui para a incidência da psicanálise no laço social contemporâneo, opondo-se à foraclusão da castração. Há, pois, uma aposta política;

2. A psicanálise e a fortiori a pesquisa clínica não demonstram a compatibilidade do universal e do singular, mas constituem uma resposta a essa antinomia no saber;

3. A psicanálise e a pesquisa clínica não estão confinadas a um papel de exploração, de formulação de hipóteses novas que caberia à abordagem experimental validar. Ao contrário, o que numa dimensão universal - no que concerne ao sujeito da fala - só poderia ser verificado caso a caso, cabe ao psicanalista e ao pesquisador que o acompanha desenvolver a lógica que permite sustentar resultados a partir do particular, levando em conta, ao mesmo tempo, as exigências da ciência;

4. Esta lógica é realmente uma das contribuições essenciais da pesquisa - começada aqui - e a ser avaliada na análise e no passe...

Sauret, M.-J. (2003). Clinical research in Psychoanalysis . Psicologia USP, 14(3), 89-104.

\begin{abstract}
Research in Psychoanalysis belongs to a new stage in modern Science: within the limits of the Mathematics' field, being it consistent, it has been concluded that there are veritable propositions that cannot be demonstrated, which reveals the incompletude of the system. This discovery has had effects upon many areas of knowledge. It is in this context that Lacan attempted to formalize the analytical discourse and to produce the matemas, which were susceptible of indexing the Real proper to psychoanalytical experience.
\end{abstract}

Index terms: Psychoanalysis. Science. Psychoanalytic clinic. Research.

Sauret, M.-J. (2003). La recherche clinique en psychanalyse. Psicologia USP, 14(3), 89-104. 


\title{
A Pesquisa Clínica em Psicanálise
}

\begin{abstract}
Résumé: La recherche clinique en psychanalyse appartient à une nouvelle étape de la science moderne: au champ des mathématiques, admettant qu'elles soient consistantes, on a conclu qu'il y a des propositions vraies qui ne peuvent pas être démontrées, ce qui a produit des effets sur les domaines divers du savoir. C'est dans ce contexte que Lacan s'efforce de formaliser le discours analytique et de produire les mathèmes susceptibles d'indexer le réel en jeu dans l'expérience psychanalytique.
\end{abstract}

Mots clés: Psychanalyse. Science. Clinique psychanalytique. Recherche.

\section{Referências}

Cliniques de recherche. (1999). Trabalho apresentado no Séminaire Interdisciplinaire d'Analyse de Discours, coordenado por François Leimdorfer e Paul Wald, IRESCO, Paris, 16 de abril de 1999.

Conditions méthodologiques d'une recherche clinique se référant à la psychanalyse dans le champ des STAPS. (1997). In M-H. Brousse, F. Labridy, \& A. Terrisse, Sport, psychanalyse et science. Paris: Presses Universitaires de France.

Freud, S. (1984). Psychanalyse. In S. Freud, Résultats, idées, problèmes (Vol. 2). Paris: Presses Universitaires de France. (Trabalho original publicado em 1923)

Lacan, J. (1985) O Seminário - Livro XI: Os quatro conceitos fundamentais da psicanálise (M. D. Magno, trad.). Rio de Janeiro: Jorge Zahar. Título original: Le séminaire de Jacques Lacan - Livre XI: Les quatre concepts fondamentaux de la psychanalyse. (Trabalho original publicado em 1964)

Lacan, J. (1995) O Seminário - Livro IV: A relação de objeto (D. D. Estrada, trad.). Rio de Janeiro: Jorge Zahar. Título original: Le séminaire de Jacques Lacan - Livre IV: La relation d'objet. (Trabalho original publicado em 1956-1957)

Lacan, J. (1998a). A agressividade em psicanálise. In J. Lacan, Escritos (V. Ribeiro, trad., pp. 104-126). Rio de Janeiro: Jorge Zahar.

Lacan, J. (1998b). Juventude de Gide ou a letra e o desejo. In J. Lacan, Escritos (V. Ribeiro, trad., pp. 749-775). Rio de Janeiro: Jorge Zahar.

Mejia, C., \& Ansermet, F. Traumatisme et langage. Notes pour une méthodologie de recher che clinique. Manuscrit.

Xenoyanni, V. (1999). Le rapport entre la science et la psychanalyse: Une question politique. Tese de doutorado, Université de Toulouse - le Mirail, Toulouse, France. 


\section{Marie-Jean Sauret}

Zapata, L. M. (1999). Clinique différentielle des névroses et analyse de discours. Essais d'application sur um corpus d'entretiens cliniques de recherche. Trabalho apresentado no Séminaire Interdisciplinaire d'Analyse de Discours, coordenado por François Leimdorfer e Paul Wald, IRESCO, Paris, 16 de abril de 1999.

Zapata, L. M. Clinique différentielle des névroses. Une approche psychanalytique à partir de l'étude du langage. Tese de psicopatologia em curso.

Zapata, L. M. (1999). Psychanalyse et méthode psychanalytique. Quelques éléments pour une approche psychanalytique de l'analyse de discours dans la recherche clinique. Trabalho inédito.

Recebido em 09.02.2004

Aceito em 13.05.2004 